\title{
REPRESENTACÃO, PARTIDOS E SOCIEDADE CIVIL NA ARGENTINA E NO BRASIL ${ }^{1}$
}

\author{
Kathryn Hochstetler* \\ Elisabeth Jay Friedman ${ }^{* *}$
}

\section{REPRESENTAÇÃOPORORGANIZAÇÕESDA SOCIEDADE CIVILNOBRASILENAARGENTINA}

Quão bem as organizações da sociedade civil (OSCs) representam os cidadãos? No contexto da crise dos partidos políticos na América Latina e em boa parte do mundo democrático, essa pergunta tem se tornado particularmente relevante. Este artigo indaga se organizações da sociedade civil (OSCs) podem desempenhar, e se de fato desempenham, a função essencial de representação nesses tempos de crise partidária. Em especial, investigamos a seguinte hipótese de crise de representação: de que "cidadãos, em todo o mundo, trocaram formas mais antigas e tradicionais de representação, como partidos políticos e sindicatos, por 'novos' modelos, como movimentos sociais, gru-

* Professora de Ciências Políticas na Universidade do Novo México. Research Fellow in Politics, Centre for Brazilian Studies. MSC05 3070, University of New Mexico, Albuquerque, NM 87131. hochstet@unm.edu.

${ }^{* *}$ Professora do Departamento de Política na Chair of the Latin American Studies Programna Universidade de São Francisco. ejfriedman@usfca.edu.

${ }^{1}$ Tradução de Elisa Larroude e revisão técnica de Diogo Antonio Rodriguez e Roberta Soromenho. Agradecemos a Silvia Ostrovsky pela assistência na pesquisa. pos informais de cidadãos e organizações não governamentais (ONGs)" (Chandoke, 2005, p.308; Bartolini; Mair 2001; Lawson; Merkl, 1988; Lawson; Poguntke, 2004; Pearce, 2004). Para tanto, examinamos práticas recentes de representação no Brasil e na Argentina, dois países em que os partidos políticos têm passado por fortes crises, após décadas de reações mistas aos seus sistemas partidários. Em momentos como esses, a substituição de partidos por OSCs deveria ser muito evidente. Como demonstramos a seguir, a crise partidária argentina era consideravelmente mais profunda que a brasileira; pela hipótese de crise de representação, portanto, deveria haver mais provas de uma troca por formas não-partidárias de representação na Argentina.

Começamos por um exame teórico a respeito de como as OSCs podem desempenhar a função de representação, usando o modelo de representação partidária como guia. Sobre a relação entre representação partidária e de OSCs, perguntamos: é complementar ou concorrente? Nas próximas seções empíricas, caracterizamos a natureza das recentes crises partidárias nesses dois países, 
bem como o papel dos chamados novos modos de representação durante e após as crises. Concluímos que não houve substituição de partidos por OSCs como mecanismos de representação dos valores e interesses dos cidadãos - e nem sequer houve tentativa de substituição (exceto por um breve período no auge da crise argentina). Em ambos os países, porém, as OSCs melhoraram a qualidade da representação para cidadãos.

\section{ORGANIZAÇÕES DA SOCIEDADE CIVIL E PARTIDOS POLÍTICOS COMO MECANISMOS DEREPRESENTAÇÃO}

Em sua essência, a representação democrática exige que os valores e interesses dos cidadãos, de alguma forma, guiem aqueles que falam por eles em processos políticos coletivos. Assim sendo, a representação é fundamental para outros processos democráticos vitais como responsabilização e legitimidade. Processos de representação são particularmente relevantes - e difíceis - em democracias de transição, e diversos estudos recentes se desafiaram a entender a representação em seus aspectos teóricos e empíricos. Há um estranho descompasso entre os estudos teóricos e a maioria dos estudos empíricos da representação. Teoricamente, a representação é um conceito disputado, com múltiplos significados de base histórica e filosófica (Manin, 1997; Pitkin, 1967; Saward, 2001). Empiricamente, os estudiosos tendem a restringir seus domínios, limitando-se ao mundo dos partidos, eleições e sistemas eleitorais, freqüentemente sem comentários ou justificativas especiais (Kitschelt, 2000; Powell, 2004; Przeworski; Stokes; Manin, 1999). Este artigo questiona essa restrição empírica e defende que OSCs também têm o potencial de desempenhar importantes funções de representação política.

Aqui definimos OSCs como organizações voluntárias que podem se formar para promover o auto-interesse de seus membros, o bem da sociedade, a provisão de serviços e (ou) advocacy, em nome de uma determinada causa ou conjunto de ideais. As OSCs costumam pretender dar voz política àqueles marginalizados do sistema político formal. Como nos partidos, há grande variação entre seus graus de institucionalização e estrutura geral. Organizações não governamentais (ONGs) tendem a ser mais estruturadas, com equipe permanente e financiamento de seus associados ou fontes externas. Movimentos sociais não são institucionalizados e freqüentemente dependem de uma rede preexistente de associações, mas tornamse visíveis apenas esporadicamente. Suas estratégias de mobilização também variam, desde lobby com tomadores de decisão a apoio ao desenvolvimento comunitário à mobilização de milhares de pessoas para manifestações públicas. O grande leque de ações e aparências de OSCs sugere que é preciso revisitar e revisar conceitos de representação democrática na região (Friedman; Hochstetler, 2002; Gurza Lavalle; Houtzager; Castello, 2006).

Como agentes de representação, as OSCs diferem de partidos de duas maneiras fundamentais: não são eleitas por um eleitorado e não governam. Dessa forma, muitos analistas hesitam em utilizar o termo representação para descrever as atividades de OSCs (Mainwaring, 2006; Norden, 2006; Peruzzotti, 2006). De forma distinta, seguimos a visão de Rehfeld (2006), que defende que tanto bom senso quanto compreensões teóricas da representação exigem uma definição mais ampla do que aquela baseada no processo eleitoral democrático. Ele vê representação sempre que existe "o juízo de algum público de que determinado indivíduo, e não outro, representa um grupo no desempenho de determinada função" (Rehfeld, 2006, p.2). Por exemplo, quando um oficial do governo da Líbia se dirige à Organização Mundial do Comércio em nome da Líbia, essa pessoa é considerada um representante, ainda que não tenha sido observada nenhuma das regras eleitorais ou democráticas de reconhecimento e representação (2006, p.1). Rehfeld observa algo ainda mais relevante para este estudo: que ONGs buscam representar os interesses daqueles que "não têm voz na seleção de seus representantes" (tais como os prisioneiros de guerra defendidos pela Cruz Verme- 
lha) e que talvez nem sejam humanos (como a relação com o meio-ambiente para grupos ambientalistas) (2006, p.1). O público pertinente dependerá da finalidade da representação; suas regras decisórias para reconhecimento podem ser ou não formalizadas e bem formuladas, anteriormente à instancia de representação. O reconhecimento do público é um fator-chave na identificação de instâncias de representação, em vez de instituições.

Com foco especial em representação e OSCs, defendemos que tanto públicos de cidadãos quanto de governo freqüentemente aceitam OSCs como representantes de valores e interesses coletivos específicos - como também fazem muitas das próprias OSCs (Gurza Lavalle; Houtzager; Castello, 2006). Para discutir como isso ocorre, utilizamos abaixo a influente formulação de V.O. Key sobre representação partidária. Para ele, partidos políticos desempenham três grandes grupos de funções representativas: partidos no eleitorado, partidos como organizações, e partidos no governo (Dalton; Wattenberg, 2000, p.5-10). Os comportamentos de OSCs reconhecidos como representativos freqüentemente se assemelham a tais funções partidárias, ainda que não sejam tão vinculadas ao processo eleitoral. Ao desempenharem tais funções, as OSCs geralmente estão menos restritas (ou habilitadas) por procedimentos e regras formais do que partidos. A maioria dos sistemas políticos tem regras formais para formação de partidos; as OSCs normalmente têm mais liberdade de se constituírem em torno de interesses específicos. Mas elas também podem estar sujeitas a regras relativas à sua formação ou atuação, especialmente quando isso envolve financiamento externo, lobby político, formulação ou implementação de políticas. Comparativamente, a flexibilidade dos processos de agregação das OSC s cria uma relação mais amorfa com seus públicos (Roberts, 2002). Em cada uma das próximas seções, discutiremos como partidos políticos desempenham as funções representativas de Key, e, então, especificaremos como OSCs também podem desempenhar a mesma função.

\section{REPRESENTAÇÃO COMO RELACIONAMENTO COM O ELEITORADO OU CIDADÃOS}

O primeiro conjunto de funções envolve as relações do partido com o eleitorado. Nesse papel, os partidos atuam como intérpretes do público votante, apresentando diferentes modos de compreender as questões políticas e ajudar os eleitores a determinarem suas identidades e interesses políticos gerais. Para tanto, alguns partidos se organizam intensamente, articulando-se profundamente com a sociedade civil. Outros, geralmente em sistemas unipartidários, têm interpenetração com o Estado. Mas muitos atuam somente como veículos eleitorais que ficam um tanto dormentes no ínterim dos ciclos eleitorais. ${ }^{2}$ Os vínculos entre partidos e sociedade já são fracos há muito tempo na América Latina, mas continuam a se enfraquecer no ciclo democrático pós-transição. Mesmo em lugares onde os sistemas partidários antes se basearam em conexões mais programáticas e participativas de massa, tais vínculos já se afrouxaram. Prevalecem as conexões carismáticas, clientelistas e personalistas. Conseqüentemente, as relações entre partido e sociedade se fundamentam quase exclusivamente nas ambições eleitorais dos partidos - uma relação tênue, com pouco interesse e legitimidade para os cidadãos (Pearce, 2004; Roberts, 2002; Taylor-Robinson, 2001). ${ }^{3}$ Há processos similares que ocorrem na Europa Ocidental, ainda que historicamente partam de níveis mais altos de integração (Dalton; Wattenberg, 2000; Lawson; Poguntke, 2004). Em novas e antigas democracias, os cidadãos são cada vez mais consumidores e não sujeitos da política (Bartolini; Mair, 2001, p.333).

Enquanto esse papel partidário concebe o público de massa como um eleitorado, as OSCs o

${ }^{2}$ A clássica distinção de Panebianco entre partidos "burocráticos de massa" e "profissionais-eleitorais" separa os partidos pelo grau de organização e penetração social (Panebianco, 1988).

${ }^{3}$ Partidos excessivamente enraizados na sociedade, chegando a sufocar outras instituições, constituem um problema mais raro na América Latina. Dois exemplos históricos de tais sistemas partidários, agora já bastante alterados, vêm da Venezuela e do México. 
concebem como cidadãos. A representação de cidadãos por OSCs também assume um formato um tanto diferente. A representação de base partidária aspira a se conectar a um público amplo, geralmente a maior parte da população adulta. Essa amplitude de escopo dos partidos é citada como um dos motivos pelos quais eles não podem ser substituídos por OSCs, muitas das quais focalizam um público mais específico (Mainwaring, 1999, p.13). As OSCs têm uma vantagem de escopo distinta. Suas atividades tendem a ser mais contínuas ao longo do tempo, enquanto os partidos são mais ativos em ciclos eleitorais. Atividades e campanhas de OSCs podem oferecer aos cidadãos, ainda que em menor número, símbolos de lealdade e identificação, educação, oportunidades para manifestações políticas e a simplificação de escolhas a todo tempo. Durante as campanhas eleitorais, as atividades de OSCs podem coincidir com as de partidos, ajudando eleitores a identificar os "candidatos ambientalistas” e assim por diante.

Na relação com cidadãos, cada mecanismo tem uma base específica em que faz suas afirmações de representação. Os partidos justificam suas reivindicações de representação com base no número de filiados ou em resultados eleitorais, uma medida relativamente direta. As OSCs, ao contrário, raramente "medem” seu apoio por eleições ou, em muitos casos, número de sócios. O apoio a OSCs pode ser rastreado pela quantidade de pessoas que apóiam suas campanhas, por exemplo, respondendo às chamadas para manifestações públicas. Pesquisas de opinião pública, às vezes, apuram a aprovação pública de segmentos de movimentos específicos de OSCs como um todo, ou valores de movimentos. O aspecto voluntário de OSCs significa que um aumento numérico é indicativo de que as pessoas confiam mais nas OSCs para conexões políticas, ainda que o surgimento de novas OSCs possa indicar também que os cidadãos pensem que as atuais OSCs sejam inadequadas.

\section{REPRESENTAÇÃO POR MEIO DE FUNÇÕES ORGANIZACIONAIS}

Os partidos, como organizações, desempenham as funções centrais de recrutar elites para cargos e gerir suas campanhas, além da tarefa crucial de levantar recursos. São funções relacionadas à articulação de interesses políticos e sua agregação em amplos programas de governo. Partidos da América Latina têm, em geral, desempenhado tais funções partidárias razoavelmente bem, com exceção da função de agregação. A natureza individualista dos partidos latino-americanos significa que muitos carecem de programas coerentes de governança (Roberts, 2002), uma lacuna que prejudica diversas outras funções partidárias.

Quanto ao argumento de que OSCs, como partidos, articulam interesses políticos, há pouca controvérsia; por exemplo, é o único argumento reconhecido por Dalton e Wattenberg (2000, p.8). Muitas OSCs entendem que essa é sua função central e afirmam representar idéias ou identidades essenciais que são negligenciadas por outros mecanismos. Essas podem ser idéias que já têm grande aceitação, mas é muito comum que as OSCs tragam idéias novas para a arena dos sistemas partidários, tais como insistir na proteção de direitos humanos em regimes autoritários (Peruzzotti, 2006; De Piero, 2005). Na América Latina, as OSCs também são ativas na agregação de interesses, na elaboração de programas de larga escala para gestão e compreensão de direitos humanos, em estratégias de desenvolvimento (especialmente alternativas ao neoliberalismo), e em reformas institucionais (Bonner, 2005; Lucero, 2001; Van Cott, 2005). ${ }^{4}$ As OSCs até desempenharam funções de recrutamento e treinamento de elites políticas, isoladamente ou em conjunto com partidos políticos. Dentre os atuais presidentes que alcançaram estatura nacional pelas OSCs, há Lula, no Brasil, um sindicalista, e Evo Morales, na Bolívia, do movimento indígena e de associações de plantadores de coca.

${ }^{4}$ Van Cott (2005) traz um contraponto interessante, examinando quando e porque alguns movimentos indígenas sul-americanos migraram para ativismo partidário pela primeira vez nos anos noventa. Antes e depois, porém, também participaram do papel das OSCs, aqui identificado como de agregação de interesses. 


\section{REPRESENTAÇÃO POR MEIO DE GOVERNOE ESPAÇO PÚBLICO}

Se candidatos partidários são eleitos, os partidos continuam a mediar interesses de cidadãos, agora em um papel singular, como tomadores de decisão. No governo, os partidos políticos organizam tanto coalizões de governo quanto de oposição e dissidência (com sorte) leais. Organizam o processo legislativo e supervisionam a implementação e a gestão de políticas. Os partidos têm mantido um monopólio de quase todas as funções de governo, normalmente preservadas em constituições nacionais ou outras legislações não-ordinárias, que exigem a filiação partidária para concorrer a cargos políticos. Os procedimentos para a agregação de votos individuais e a alocação dos cargos com autoridade decisória são estabelecidos por complexas regras eleitorais. Em democracias, elas também estabelecem procedimentos para reavaliação periódica pelos eleitores e a possibilidade de substituição. O resultado concreto pretende promover estabilidade de governo por meio da continuidade que vai além de indivíduos e determinar seqüências de responsabilização por atos governamentais. Boa parte da avaliação dos partidos como mecanismos de representação analisa as conseqüências de variação dessas normas (Carey, 2003; Crisp et al, 2004; Mainwaring; Scully, 1995). Ao longo do tempo e do espaço, tem variado bastante a capacidade de os partidos latino-americanos assegurarem tais funções governamentais (Mainwaring, 1999a, 2006).

Somente os partidos políticos têm um espaço representacional que lhes permite diretamente ter a autoridade de tomar decisões para a sociedade como um todo, para além de seus eleitores específicos: no governo, governam. As OSCs, por sua vez, promovem os interesses de seus públicos respectivos no espaço público - isto é, na esfera de debate e de discussão coletivas, externas às decisões políticas formais (ainda que também possam, é claro, fazer lobby internamente às instituições estatais). Essa esfera pública tem sido historicamente subdesenvolvida na América Latina, mas tem crescente potencial. Na concepção de Avritzer, a esfera pública é um lugar em que associações podem trazer questões para a agenda pública, introduzir práticas políticas alternativas e até desenvolver novos formatos institucionais para abordar suas questões (Avritzer, 2002, p.7). Avritzer argumenta que essas são funções claramente importantes e essenciais à democratização.

Ainda que não sejam formas de tomada de decisão com autoridade que vincula a sociedade, as ações de OSCs, na esfera pública, podem desempenhar algumas das mesmas funções dos partidos no governo. De maneira particularmente dramática, os protestos de massa organizados parcialmente por OSCs são o novo poder moderador para os presidentes sul-americanos, sancionando sua capacidade de continuar a governar ou atando-os antes que terminem seus mandatos "fixos" (Hochstetler, 2006a, p.403). As OSCs também exercem funções de responsabilização social, monitorando os atores governamentais e a qualidade administrativa do governo (Smulovitz; Peruzzotti, 2000).

\section{REPRESENTAÇÃO POR PARTIDOS POLÍTI- COSE(OU) OSCS?}

Até agora, a discussão especificou os papéis de representação que partidos e OSCs podem desempenhar. Esta seção focaliza a relação entre eles. Partidos políticos e OSCS prosperarão juntos, como mecanismos de representação, ou o sucesso de um implica um desfortúnio do outro? A emergente literatura sobre crise de partidos políticos freqüentemente presumiu que o crescimento de modalidades não-partidárias de representação é, no mínimo, sintomático do declínio de legitimidade e quantidade de sócios de partidos, se não diretamente causal. ${ }^{5}$ Esse argumento tem sua contraparte na literatura sobre movimentos sociais, que freqüentemente defende que políticas de

${ }^{5}$ Argumento resumido em Thomas, 2001; ver também Lawson; Poguntke, 2004; Mainwaring, 2006, p.15; Nordon, 2006. 
base partidária podem distorcer e sobrepujar formas alternativas de participação. ${ }^{6}$

Em ambos os lados dessa discussão, autores tendem a concordar que a verdadeira democracia será prejudicada sem o mecanismo cuja autonomia e existência são alvo de ataques. Dessa forma, por exemplo, livros sobre partidos políticos na América Latina regularmente enfatizam que "organizações não-partidárias como sindicatos, movimentos sociais e ONGs não podem ser substitutos de partidos em seu papel de gerar (Bruhn), preservar (McGuire), ou aprofundar (Roberts) democracia (Levitsky, 2001b, p.105).” Do mesmo modo, a democracia eleitoral por meio de competição partidária é vista como a preservação de uma série de instituições de elite na recente política latino-americana, sem melhoria das "experiências vividas por cidadãos” (Foweraker, Krznaric, 2002, p.33), e até, com o neoliberalismo, levando à "subarticulação de interesses sociais, excessiva atomização social, e aquiescência política” (Kurtz, 2004, p.263).

Na contramão desses argumentos de somazero, há um crescente número de acadêmicos que sugerem que os diferentes mecanismos de representação podem se relacionar de maneiras complementares. Oargumento geralmente começa com a compreensão de que os partidos são atores centrais na representação de valores e interesses de cidadãos, mas que outros atores podem ajudar a solucionar alguns dos problemas da democracia eleitoral. A participação não-partidária pode simplesmente ser uma opção melhor do que as eleições para a expressão de determinados tipos de preferências, dado que o voto é apenas uma opção para cidadãos cada vez mais capacitados em democracias, dentro de um repertório mais amplo de estratégias de ação (Fuchs; Klingemann, 1995, p.432; Dalton; Scarrow; Cain, 2004). Como discutimos acima, partidos e OSCs têm diferentes vantagens de escopo na relação com o público de massa (Goldstone, 2004; Kitschelt, 2003). Por fim, no-

${ }^{6}$ Argumento discutido e criticado em Hellman, 1992; ver também Alvarez, 1990; Panizza, 2005; Zibechi, 2005. vas formas de organização podem "atuar como guardiões republicanos", fornecendo informações que aprimoram a responsabilização (O'Donnell, 1998, p.122; Fuchs; Klingemann, 1995, p.435-36; Smulovitz; Peruzzotti, 2000). Nessa visão, os diferentes mecanismos de representação se complementam e se aprimoram. Também é possível que ambas as formas de representação sejam fracas, com nenhuma melhorando as falhas da outra (Chandoke, 2005).

Para escolher dentre esses argumentos, examinamos evidencias recentes a respeito de quão bem partidos e OSCs têm desempenhado suas funções organizacionais e de público de massa no Brasil e na Argentina. Concentramos nelas por serem as funções em que partidos e OSCs mais coincidem e podem competir, especialmente em tempos de crise partidária. A literatura sobre partidos, mais desenvolvida e com dados quantitativos disponíveis, fornece claras relações de indicadores que usaremos (Mainwaring, 2006, p.15; Poguntke, 1996; Webb, 2005). Eles incluem dados de survey a respeito do desafeto com partidos em geral, erosão de identificação partidária, quantidade de eleitores que comparecem às urnas, maior incerteza eleitoral e crescente quantidade de votos em partidos e candidatos "outsiders". Para as OSCs, examinaremos tanto o surgimento de novas organizações - e especialmente novos tipos de organizações - e as fortunas de organizações existentes. Apresentaremos evidências a respeito das variações de apoio, dentre diferentes públicos potenciais, para determinadas campanhas e organizações, bem como quaisquer dados de survey disponíveis. Por fim, rastrearemos os esforços das OSCs na articulação e agregação de interesses de grandes públicos.

\section{CRISE PARTIDÁRIA E REPRESENTAÇÃO ALTERNATIVA NAARGENTINA}

A sociedade argentina rebelou-se fortemente contra sua classe política em meados de dezembro de 2001. Sob a bandeira de que se vayan todos, desde defensores de direitos humanos e Mães da 
Praça de Maio a movimentos de desempregados foram às ruas protestar contra o fracasso dos mecanismos formais de participação. Em 2002, parecia que um conjunto diverso de OSCs não-partidárias estava construindo uma arena alternativa para participação política horizontal e localizada. Mas quão profunda foi essa mudança? O sistema partidário argentino está em uma fase de incerteza, mas nem todos os partidos entraram em crise. $\mathrm{E}$ ainda que a sociedade civil tenha oferecido formas alternativas de representação, elas não estão substituindo a política de partidos.

\section{Colocar a crise em contexto}

Historicamente, o sistema partidário argentino era classificado entre bi-partidário e moderadamente multipartidário; além dos dois partidos dominantes, o peronista Partido Justicialista (PJ) e a União Cívica Radical (UCR), havia considerável representação de terceiros na Esquerda e na Direita. Os partidos dominantes refletiam a principal divisão de classe, com apoio das classes baixas e trabalhadoras para os Peronistas e apoio das classes médias e altas para os Radicais, ainda que ambos os partidos se dirigissem a pessoas em todo o espectro econômico. As regras constitucionais reforçavam o controle bi-partidário: eleições simultâneas, nesse sistema presidencialista, produzem o efeito legislativo de "carona" de eleições presidenciais, em que o vencedor leva tudo. Mas outras regras permitiam representação mais ampla: eleições legislativas com listas partidárias e representação proporcional; estrutura federal; e a eleição indireta do Senado por assembléias das províncias. Tais -fatores levaram a mais partidos que ocupavam cargos, especialmente nas províncias (Calvo; Escolar, 2005; McGuire, 1995, p.231).

A incapacidade de os partidos responderem ao desastre econômico que, em meados de 2002 , correspondia a $50 \%$ de pobreza e $25 \%$ de desemprego deixou o sistema político em caos. Entre 1997 e 2002, a confiança geral dos argentinos nos partidos políticos caiu vertiginosamente: uma queda de $86,2 \%$, a maior da América Latina, que terminou com apenas quatro por cento do eleitorado expressando confiança nos partidos (Latinobarometer, apud Sanchez 2005, p.457). Essa desconfiança se refletiu no péssimo desempenho das eleições de 2001: pela primeira vez, somente $30 \%$ do eleitorado optaram por votar em um dos dois grandes partidos, e $15 \%$ votaram nulo ou em branco. Mesmo a maioria do PJ no Senado se baseava em 30\% dos votos distritais (Calvo; Escolar, p.211-212). Como foi dito à época, o vencedor dessa eleição foi "ninguém": mais eleitores preferiram não votar ou inutilizar suas cédulas a votar em um candidato.

Ainda que esses números sugiram que os partidos tenham entrado em crise aguda, uma análise detalhada do comportamento eleitoral traz uma história diferente. Como uma pista geral a respeito das atitudes da população, a participação eleitoral mostrou alguma recuperação do ponto baixo de 2001. Nas eleições presidenciais de 2003, o índice de abstenção foi $22 \%$ mais baixo do que em 2001, e os votos brancos e nulos, com $2,6 \%$, tiveram o índice mais baixo desde 1983. Ao todo, 77\% dos eleitores registrados votaram (Sanchez, 2005, p.468). Ainda que o voto tenha sido dividido entre um leque de candidatos presidenciais, metade era peronista e a outra metade tinha origens na UCR (2005, p.461-465,471). A incapacidade de os partidos se unirem por trás de um candidato demonstra a erosão de identidade partidária até entre as elites partidárias, mas os grandes partidos ainda são atores relevantes.

Apesar de controlar cerca de um quarto dos estados e municípios, a UCR "efetivamente desapareceu como formação política de nível nacional representante da classe média, uma identidade e um papel que datam da década de 1890" (p.472, 467). Aliás, na primeira década de democracia, o declínio de poder eleitoral nacional dos dois grandes partidos conjuntamente considerados (de 92\% a $67 \%$ do voto presidencial e $86 \%$ a $65 \%$ do voto legislativo) se deveu principalmente ao desempenho da UCR (Torre, 2003, p.649). 
O PJ - que obteve o primeiro e o segundo lugar nas eleições presidenciais de 2003 - parece, como a fênix, estar ressurgindo das cinzas. Torre (2003, p.659) afirma que existe um "núcleo duro" de apoiadores do PJ, cerca de 37\% do eleitorado, que votarão no partido independentemente das políticas que ele promover no cargo. A lealdade histórica ao partido de Juan e Evita Perón (Sanchez, 2005, p.468) é reforçada por recompensas materiais. A bem-sucedida transição do partido da base sindicalista para vínculos clientelistas, durante a neoliberal década de 1990, na gestão do Presidente Carlos Menem, significou que mesmo os eleitores mais pobres continuam a ter acesso limitado a recursos (Delamata, 2004; Auyero, 2001; Levitsky, 2001c). O desenho institucional também contribui para sua duração no poder: o PJ ganha uma quantidade desproporcional de cargos, especialmente no Senado, por causa de sua super-representação em pequenas províncias (Mustapic, 2005; Torre, 2003).

Entretanto, uma leitura concorrente do voto peronista defende que ele não é estável, mas sim composto de "configurações distintas de eleitores fiéis, eleitores ocasionais, e eleitores estratégicos" (Calvo; Escolar, 2005, p.197). Analistas argumentam que, em vez de existir um único partido dominante em âmbito nacional, o sistema partidário foi desnacionalizado, com perfis bastante diferentes pelo país: reformas constitucionais e eleitorais no âmbito da província reforçaram partidos de domínio local (2005, p.197).

Qualquer que seja a visão dos analistas a respeito do atual sistema partidário, é provável que concordem com a leitura de Sanchez (2005, p.473) de que ele está agora "em um estado altamente fluido". Torre afirma que eleitores de Centro-Direita e Centro-Esquerda têm sido especialmente voláteis, com práticas que simultaneamente aprimoram e prejudicam a democracia de base partidária. Cidadãos mais exigentes, educados pelos movimentos de direitos humanos e civis das décadas de $1980 \mathrm{e}$ 1990, recusam-se a manter fidelidade a partidos corruptos, ineficientes e ideologicamente incoerentes diante de crises. Entretanto, sua volatilidade tem significado que são as coalizões fracas ou par- tidos novos que têm mais sofrido o impacto de seu desejo de punir governantes inadequados, enquanto o PJ mantém seu apoio. Torre (2003, p.15) descreve o impacto desses eleitores como um paradoxo: "aquilo que é positivo sobre a crise, em termos de expansão da democracia partidária, também é a causa de um impacto institucional negativo".

Apesar de não estarem desempenhando seu papel representacional histórico, os partidos políticos e o sistema partidário não estão inteiramente em crise. Tendo ou não um "núcleo duro" de seguidores, $\mathrm{o} \mathrm{PJ}$ parece ter sobrevivido à reviravolta de 2001-2002. Como será demonstrado a seguir, sua capacidade de oferecer benefícios materiais aos seus apoiadores também tem impacto no grau relativo de autonomia de outros mecanismos de representação. Contudo, os partidos não têm conquistado a confiança (recente) de muitos cidadãos. O que oferece a sociedade civil?

\section{Formas emergentes de representação: auto- nomia, cooptação e cooperação}

A sociedade civil estava pronta para se revoltar em 2001. Na década de 1990, os deslocamentos econômicos provocados pelas reformas neoliberais de Menem geraram devastação nas províncias. A resposta estabeleceu um padrão que marcaria a década. Praticamente cidades inteiras se levantaram nas províncias de Salta, Jujuy e Neuquén, atacando repartições governamentais e cortando grandes vias de transporte, em demonstrações caracterizadas como espontâneas ${ }^{7}$ contra condições vertiginosamente decrescentes de trabalho e vida. ${ }^{8}$ Nessas áreas e na Grande Buenos Aires, uniram-se movimentos de desempregados, exigindo

Alguns observadores constataram que redes políticas preexistentes fomentaram essas mobilizações (Auyero, 2005, 2004).

3 Também houve protestos significativos contra a impunidade por violações de direitos humanos, tais como as marchas para exigir justiça nos casos de María Soledad Morales, uma jovem cujo assassinato foi acobertado pela polícia na tentativa de proteger seus assassinos politicamente bem-relacionados, e José Luis Cabezas, um fotógrafo que foi assassinado por causa de seus esforços para expor brutalidade policial e a corrupção política. 
que os governos das províncias e nacional fornecessem seguridade e emprego (González Bombal, 2003; Svampa, 2005; Svampa; Pereira, 2005).

Em seu aspecto mais radical, esses movimentos buscaram romper com formas de representação que constatassem ser fundamentadas em relações clientelistas, dependentes. Promoviam relações horizontais e tomada de decisão por democracia direta. Como explicou um participante:

Não é que houve uma decisão de ser horizontal... [as pessoas] simplesmente se encontraram, sentindo grande rejeição por... todos que ocupavam espaços no Estado, ou se organizavam para ocupar espaços no Estado... com uma espécie de decisão de "vamos fazer nós mesmos" (Sitrin, 2005, p.iv-v, 27).

À medida que a crise se ampliava e se aprofundava, espalhava-se a rejeição da representação de base partidária e eleitoral em favor de processos políticos autônomos.

Esses novos movimentos foram inspirados por seus antecessores. A geração de grupos de direitos humanos que se opuseram à autoritária "Guerra Suja” (1976/1983) continuava seu trabalho após a transição para a democracia. Apesar de dividido a respeito de quanto cooperar com governos que não enfrentavam adequadamente a impunidade do passado, o movimento também inspirou uma segunda geração (ainda que coincidente) de proponentes de direitos (Peruzzotti, 2002). Essas organizações, como o exemplar Centro de Estudos Legais e Sociais (CELS), lutaram contra a impunidade enquanto fortaleciam instituições democráticas para proteger direitos humanos e civis.

Ainda mais próximo dos novos movimentos sociais e de sua rejeição da "política de sempre", havia um novo movimento sindicalista (Bielsa et al, 2002, p.71). Na década de 1990, sindicatos de professores e servidores públicos lideraram os esforços de formação do anti-neoliberal Congresso de Trabalhadores Argentinos (CTA) (Rodríguez, 2006). Com mudanças na organização social e política, o CTA oferecia uma nova forma de representação para um público muito mais diverso. Em vez de rejeitar eleições, esse movimento buscou torná-las mais inclusivas, ao menos internamente. Recusava identificações partidárias e realizava eleições diretas de sua liderança. Acolhia membros não-sindicalizados, buscando ser uma "ferramenta de organização que unificasse todo o mundo do trabalho, inclusive trabalhadores informais e desempregados" (Rodríguez, 2006). Por fim, buscou conectar formas de organização baseadas no local de trabalho com formas novas, declarando que seu público-alvo de mobilização era "a fábrica nova que está no bairro" (Camarero; Pozzi; Schneider, 1998; www.cta.org.ar).

No auge da crise política, muitos desses atores se uniram na sua crítica à legitimidade dos partidos e da classe política. Isso estava mais fortemente articulado na exigência da sociedade de que "devem ir todos". Esse formato, originalmente levantado nas grandes demonstrações contra o governo de la Rúa ${ }^{9}$ em dezembro de 2001, foi ecoado por aqueles que fortemente recriminavam personagens políticas em espaços públicos, desde cafés a aeroportos, responsabilizando-os pelo fracasso do sistema político.

Conforme crescia essa onda de protesto, sua capacidade de mobilização e interpretação aproveitou símbolos e lutas passadas. Um membro de uma assembléia de bairro recordou sua experiência do maior dia de protesto em dezembro: "Eu liguei o rádio e escutei que havia pessoas indo à Plaza de Mayo, que as Mães da Plaza de Mayo estavam sendo presas... Eu fui imediatamente" (Sitrin, 2005, p.3). A essa altura as Mães já haviam expandido seu discurso para refletir o contexto contemporâneo, com slogans como "os desaparecidos de ontem são os desempregados de hoje" (ver Borland, 2006, esp. p.9). As repressões às vezes fatais aos desempregados persuadiram muitos gru-

${ }^{9}$ Os protestos foram catalisados pelo congelamento das contas bancárias domésticas pelo governo central, numa tentativa de estancar a hemorragia de capital que saía do país antes da forte desvalorização. Cidadãos de classe média se juntaram a desempregados em enormes demonstrações na Plaza de Mayo, no centro, em 19 e 20 de dezembro. Quando de la Rua declarou estado de emergência e a Polícia Federal usou força letal contra os protestos, estes só aumentaram. Para um detalhamento diário a respeito de como se desdobraram essas demonstrações, ver Iñego Carrera e Cotarelo 2004. 
pos de direitos a respeito do paralelo entre exigências novas e antigas.

Pouco após os protestos e a renúncia de De La Rúa e do presidente interino que o sucedeu, houve um boom de organização econômica e social de maneira autônoma. Assembléias populares ou de bairro, um fenômeno predominantemente da classe média, seguiram os passos dos movimentos emergentes de desempregados (Bielsa et al, 2002, p.24), envolvendo-se em ações de protesto - inclusive os famosos batedores de panelas (cacerolazos), o bloqueio de vias (piquetes) e escrachos (escratches) de personagens públicas bem como em tomada horizontal de decisões em questões de importância local. A afirmação de democracia direta em lugar da democracia representativa (p.15, 31) concretizou-se nas horas despendidas em discussão aberta. Um participante observador relatou um ritual "quase compulsivo" de votar todas as pequenas decisões, com essa auto-representação sendo "o ato pelo qual vizinhos se tornaram membros da assembléia, a personificação (la puesta en escena) da condição de serem iguais, vinculados horizontalmente entre si" (Bergel, 2003, p.87). Alguns trabalhadores ocuparam e reabriram fábricas fechadas, expandindo-se em um movimento de fábricas "recuperadas" (Lavaca 2004; Korol, 2004). Movimentos sociais ofereciam oportunidades não só em classe, mas também em gênero; por meio deles, mulheres pobres e da classe média encontraram a "possibilidade de alcançar espaços públicos" (Sanchís, 2006; Di Marco, 2006).

Os movimentos uniam forças, com algumas assembléias assumindo projetos tais como instalações médicas para auxiliar os trabalhadores de fábricas recuperadas e desempregados. Suas estratégias compartilhadas (auto-organização, deliberação horizontal) articularam os valores e demandas de um grande público. Ou, nas palavras de um canto de protesto, "bloqueio de ruas ou batendo panelas, a luta é uma só” (Piquete y cacerola, la lucha es una sola) (Bielsa et al, 2002, p.101). Havia, porém, diferenças em termos de sua recepção pelos públicos-alvo: em 2002, as assembléias ti- nham o dobro do nível de aceitação (80\%) pela população geral do que os movimentos de desempregados (40\%) (2003, p.26).

As crises dos partidos e das instituições políticas criaram uma abertura para outros grupos marginalizados. Sua exclusão da política mainstream se tornou um ativo, dado que suas reputações "imaculadas" e exigências "puras" eram vistas como engajamento político ético. Fernando Ojeda e Cristina Lescano, da organização socioambiental de base El Ceibo, notaram que seu projeto de empoderamento popular e reciclagem urbana já tinha quase dez anos em 2001, quando as pessoas começaram a procurar programas locais eficazes para ajudar os que não tinham emprego regular (Lescano, 2006; Ojeda, 2006). De repente, todos queriam trabalhar com eles, e eles puderam expandir e institucionalizar seus programas. Líderes da Comunidade Homossexual da Argentina (CHA) descobriram que a crise os ajudava a avançar sua proposta de uniões civis em Buenos Aires, promulgada em dezembro de 2002. Como afirmou Marcelo Sundheim, "a sociedade estava muito insatisfeita com os políticos, e o sentimento de que era preciso haver justiça... estava crescendo muito rapidamente. Aquela situação contextual era muito forte e foi decisiva para o projeto de união civil" (Sundheim, 2006). "Atores sociais" como a CHA preenchiam uma necessidade básica: "À medida que o projeto avançava e nós íamos às ruas, muitas pessoas nos aplaudiam... Não éramos importantes como líderes políticos, mas éramos referências éticas [ou seja]... pessoas que não mentiam... referências... de uma mudança, de algo mais justo" (2006).

OSCs institucionalizadas também encontraram na crise uma oportunidade de avançar suas agendas de reforma. Entre 2000 e 2004, 16 ONGs foram formadas com foco em reforma do Estado (CIPPEC, 2006). Como a crise econômica piorou as condições de vida em um momento em que o estado estava "sumido", isso "abriu o caminho para uma boa pressão por parte das ONGs para... exigir o fortalecimento de instituições" (Martín Vezzulla, 2006). Como exemplo primário, um grupo de 
ONGs, liderado pela Associação de Direitos Civis (ADC) e incluindo CELS e o grupo ambientalista nacional FARN, decidiu abordar os problemas com a desabonada Suprema Corte. Com uma interpretação da exigência de que "devem ir todos" se aplicava a mais do que os próprios juízes, elas ofereceram críticas ao desenho da Corte, inclusive ao processo de nomeação. O grupo propôs reformas no documento "Uma Corte pela Democracia." Em 2003, o Presidente Nestor Kirchner assinou um decreto aceitando a maior parte das suas idéias (Asociación por los Derechos Civiles, 2005, p.I.1). Assim, uma coalizão de ONGs foi reconhecida como tendo agregado, e agora como representante interesses sociais perante o público a que se dirigia, tomadores de decisão estatais.

Aqueles que focavam em reforma institucional não se declaravam substitutos da representação eleitoral democrática de partidos políticos. ${ }^{10}$ Como explicou Roberto Saba, diretor executivo da ADC, "ONGs de direitos humanos não têm necessidade de provar que representam alguém. Estão lutando pelos direitos das pessoas". Ele ofereceu um exemplo de seu papel singular, contando uma história de ter deposto perante o Congresso durante um debate sobre uma lei de liberdade de informação. Quando uma poderosa senadora tentou negar sua legitimidade como interlocutor, dado que ela representava diretamente os milhares de eleitores que a elegeram, ele respondeu: "Eu não represento nenhum eleitor. Estou aqui para assegurar que as leis sejam observadas, para cumprir a constituição". Ele disse que "ter de demonstrar que uma posição é apoiada por um determinado grupo de pessoas" era um truque ou uma armadilha para aqueles que promoviam

${ }^{10}$ Organizações que alegam representar um setor também vêem um papel na reforma institucional. José Blumenfeld, um membro de Memória Ativa, que representa "o grupo de familiares e amigos de familiares" dos mortos na explosão por bomba da Associação Mutual Israelita da Argentina em 1994, explicou que, juntamente com sua luta particular por verdade e justiça, seu objetivo “ajuda a melhorar a saúde institucional da República." Ele ofereceu provas, como sua ação judicial no país e o recurso, deferido, à Comissão Inter-Americana de Direitos Humanos, pedindo o julgamento desta, o que levou o governo a aceitar a responsabilidade por que levou o governo a aceitar a responsabilidade por
deixar de prevenir a explosão por bomba e negando justiça a suas vítimas (Blumenfeld, 2006). os direitos individuais, pois seu trabalho será sempre "contra-majoritário" (Saba, 2006). ${ }^{11}$ Ainda que não majoritários, seu trabalho claramente promove interesses dos cidadãos que são fundamentais para as democracias.

Observadores acadêmicos escreveram com entusiasmo a respeito da forma como esses novos atores desafiaram e pareciam substituir formas institucionais e partidárias de representação (Svampa, 2003). Acharam particularmente inspirador o desafio dos novos movimentos: "Os movimentos sociais autônomos da Argentina... começaram a articular uma política nova e revolucionária... uma política da vida diária” (Sitrin, 2005, p.iii); as assembléias de bairro ofereceram uma nova radicalidade 'irreversível'... que tomou corpo na nova geração” (Bielsa et al, 2002, p.55). Mas desenvolvimentos contemporâneos revelam um panorama mais sóbrio da atual política de representação.

As políticas do presidente Kirchner provocaram uma divisão entre atores da sociedade civil, com alguns abraçando seus esforços e outros rejeitando suas técnicas políticas familiares. Como seus maiores rivais à presidência eram do seu próprio partido, ele buscou aliados não-tradicionais, inclusive grupos de direitos humanos, o CTA, intelectuais progressistas e movimentos de desempregados. Suas ações para reverter a impunidade de décadas daqueles responsáveis pela "Guerra Suja", inclusive uma "limpeza" militar, agraciou-o perante diversas organizações de direitos humanos. De início, parecia que questões mais recentes também estavam em pauta: ele aceitou as reformas da $\mathrm{Su}-$ prema Corte e recusou-se a reprimir assembléias e desempregados (Gaudin, 2005).

Alguns grupos se aliaram a um governo que parecia disposto a lidar com suas necessidades. Em um símbolo marcante, a líder das Mães, Hebe de Bonifini, declarou desnecessária a "Marcha de

${ }^{11}$ Essa defesa de seu papel - cumprir a constituição e proteger direitos individuais - pode ser usada para responder a qualquer analista que veja o financiamento estrangeiro da ADC e de outras como determinante de sua agenda, assim tornando-as não-representativas de interesses domésticos (majoritários). Ver Norden, 2006. 
Resistência” anual, de 24 horas, porque "o inimigo não está mais na Casa do Governo” (Clarin, 2006). Dois líderes proeminentes dos movimentos de desempregados e de bairro entraram para o governo Kirchner como Subsecretário de Habitação Social e Terra e Diretor Nacional de Assistência Comunitária no Ministério do Desenvolvimento Social. Estas OSCs, que deram forte apoio ao bem-sucedido pleito presidencial da esposa de Kirchner, aceitam um partido como tendo oferecido representação legítima, e trabalham para fortalecer sua posição. Como antes, há incentivo material para esse apoio; Kirchner continuou e aumentou os benefícios de assistência social de seu antecessor. Em dezembro de 2001, 1\% da força de trabalho recebia subsídios do governo; em abril de 2003, eram 18\% (Sanchez, 2005, p.468-469). Segundo uma estimativa de 2005, o plano nacional de seguridade tinha 1.700,000 beneficiários (Svampa; Pereyra, 2005).

Outros oferecem uma gama de críticas ao atual governo, desde rejeição direta a uma avaliação mais cautelosa das ações contemporâneas. María Adela Antokoletz, das Mães da Plaza de Mayo Linha Fundadora, distingue entre o apoio de Kirchner à celebração das vítimas da Guerra Suja, proclamando o mais notório centro de tortura em um museu à memória, e as necessidades que ainda restam tanto de verdade quanto de justiça (Antokoletz, 2006). Questões mais contemporâneas foram ofuscadas pelo foco no passado, pois persiste a impunidade dos atuais responsáveis por violações de direitos humanos (Walger, 2006). ${ }^{12}$

Aqueles que rejeitam o partido governante e seu presidente carismático fazem suas críticas por veículos partidários e não-partidários. Setores do movimento dos desempregados cooperam com ou são liderados por partidos de extrema esquerda (Delamata, 2004), assim como diversas das as-

${ }^{12} \mathrm{O}$ vínculo entre impunidade passada e injustiça atual é marcadamente exemplificado por acontecimentos recentes: logo após o proferimento de uma sentença de prisão perpétua em um dos primeiros casos reabertos contra um chefe de polícia que ordenou o assassinato e a tortura de prisioneiros durante a Guerra Suja, desapareceu uma das principais testemunhas da acusação - e outra recebeu ameaças de bomba em seu trabalho (Valente, 2006). sembléias de bairro já declinantes. O Coordenador Contra Repressão Policial e Institucional (CORREPI), que é politicamente independente, usa o sistema judiciário e as organizações educacionais de base para lutar contra a contínua repressão física utilizada pelas forças de segurança do estado (Verdú, 2006).

A exigência de 2001 por uma renovação da vida política falhou: não houve uma substituição da classe política. Juan Martin Vezzulla (2006), da FARN, reflete que o intenso surgimento de participação cidadã inovadora foi fugaz:

Esse movimento por parte dos cidadãos não durou muito... havia o axioma de que 'devem in todos' e na verdade não se foi nenhum. E os cidadãos rapidamente voltaram para o problema mais diário da crise, de seus próprios problemas econômicos, sociais etc...

O CTA relatou, em 2004, que quase $90 \%$ dos protestos sociais contemporâneos atraíram menos de 5.000 participantes (Lozano et al, 2004). Alguns entendem que o clientelismo é responsável por esse refluxo de energia. Como afirma Néstor Jeifetz, presidente de um movimento habitacional, a "superseguridade" levou muitos grupos a "práticas que geram dependência e perda de dignidade” (Jeifetz, 2006). Kirchner agora aposta em uma "receita" de estratégias para "integrar, cooptar, disciplinar e/ou isolar" movimentos sociais (Sardá 2007; Svampa; Pereyra, 2005, p.107). A persistente desilusão com os partidos foi afirmada em entrevistas de 2006, em que perguntas a respeito dos papéis representacionais das OSCs eram freqüentemente respondidas por uma forte dissociação com fundamentos partidários, i.e., alegações de representar quantidades de indivíduos. ${ }^{13}$

Ainda que a liderança partidária - especialmente do sempre presente PJ - permaneça no mesmo lugar, a sociedade civil continua fornecendo alguns aspectos de representação, mesmo que agora em formato menos dramático. Do lado institucionalizado, Saba (2006) nota que “a socie-

${ }^{13}$ Como dito por Pablo Secchi, de Poder Cidadão, "Não queremos nem dizemos que representamos alguém." (2006). 
dade civil evoluiu" desde a década de 1990 e há consciência da necessidade de profissionalizar os esforços de articulação, com bastante envolvimento em lobby para reformas. Do lado dos movimentos, ativistas de direitos sexuais e reprodutivos atribuem a ampliação de suas coalizões e o aprimoramento de sua capacidade de mobilização à experiência de larga colaboração durante a crise (Rachid, 2007; Schvartzman, 2007).

\section{CRISE PARTIDÁRIA E PARTICIPAÇÃO EMER- GENTE NO BRASIL}

Há muito, os partidos políticos brasileiros são criticados como alguns dos mais fracos da América Latina, apesar de o Partido dos Trabalhadores (PT) ter se destacado como um partido extraordinariamente programático e disciplinado (Hunter; Power, 2005; Samuels, 2006). Quando surgiram grandes acusações de corrupção contra o PT em 2005, isso gerou uma sensação de crise para o primeiro governo nacional do PT e para o próprio partido. Por causa da natureza ostensivamente extraordinária do PT, sua crise provocou um questionamento generalizado a respeito de problemas com a representação de base partidária, ainda que não tenha tido o mesmo alcance que na Argentina.

Esta seção inicia com uma descrição da representação de base partidária no Brasil até e após a crise de corrupção de 2005. Passa, então, para as respostas de OSCs à crise e para as formas com que tentaram remediar o que muitas viam como um fracasso da democracia representativa em seu país. Como muitas tinham ligações históricas com o PT, suas respostas começaram por reafirmar sua própria autonomia. A crise não resultou em muitas novas organizações, mas promoveu um grande esforço de mobilização de redes (networking) entre as organizações existentes, que tentavam agregar e articular alternativas políticas - agora sem o PT. Seus esforços obtiveram um misto de respostas, tanto do governo quanto do público cidadão.

\section{Representação partidária, corrupção e crise}

Como é notado, os partidos políticos brasileiros têm uma reputação antiga como fracos e incoerentes, mal conectados com a sociedade (Ames, 2001; Mainwaring, 1999b). Diversos estudos recentes defendem que o sistema partidário brasileiro é consideravelmente mais capaz de governar do que sugere sua reputação, com base em comportamento partidário disciplinado no Congresso (Amorim Neto, 2002; Figueredo; Limongi, 1999). Em questões mais centrais a este artigo - a importância de fisiologismo, a falta de governança programática, e os vínculos fracos com cidadãos, há mais consenso sobre as fraquezas dos partidos brasileiros. De diversas maneiras, o sistema representativo proporcional de lista aberta no Brasil cria e recria esses atributos.

Em 1998, ao término do primeiro mandato completo de um presidente civil no Brasil, os brasileiros julgavam suas instituições políticas com alguns nuances. No tocante aos níveis de confiança nas instituições como um todo, os brasileiros estavam exatamente no ponto central dos países da América Latina: classificavam bem suas tropas e mal sua polícia e sua televisão, e sua confiança nas instituições de governo era próxima da mediana. Vinte por cento expressaram muita ou considerável confiança em seus partidos, situando-se entre o Uruguai, no alto, com 34\%, e o Equador e a Venezuela, com $15 \%$, no patamar mais baixo de confiança manifestada (Latinobarometer, apud Turner; Carballo, 2005, p.181). Em 2005, somente 13\% dos brasileiros expressavam tais níveis de confiança, mas ainda estavam próximos da média latino-americana de 13,8 (Latinobarometer, apud Sanchez, 2005, p.457). Medidas de partidarismo - expressas pela auto-identificação de indivíduos com determinado partido - contam uma história similar. A maior parte dos brasileiros não se considera adepta de algum partido, mas a grande maioria dos que assim se consideram já esteve comprometida com o PT. A preferência pelo PT "cresceu mais ou menos consistentemente de $6 \%$ em 1989 para 24\% no final de 2004 (Samuels, 2006, 
p.5).” Contudo, em agosto de 2005, com o escândalo da corrupção chegando ao auge, a preferência autodeclarada pelo PT caiu para $18,5 \%$ e ainda estava em 18,8\% em setembro de 2006, mesmo com Lula, o candidato do PT à presidência, prestes a vencer a reeleição (DataFolha, 2005, 2006). Os antigos partidários do PT não migraram para outros partidos; o declínio gradual do PMDB o levou a manter apenas 7\% dos partidários comprometidos e outros partidos flutuam em $5 \%$ ou menos (Samuels, 2006, p.5). A única categoria em ascensão em 2005 e 2006 foi "sem preferência partidária”, apesar da recuperação nos índices de aprovação do Congresso e de Lula (DataFolha).

Assim, de diversas maneiras, os dados dos surveys apóiam o argumento de que o ano de 2005 trouxe uma crise nas relações dos partidos com o eleitorado, especialmente para o PT. Eleitores não se identificam com partidos nem os consideram em alta estima; $57 \%$ dos brasileiros entrevistados em agosto de 2006 nem sequer lembravam em quem haviam votado para deputado federal e deputado estadual nas eleições de 2002 (DataFolha, 2006). Em 2005, apenas $42 \%$ dos brasileiros pensavam que não se podia ter uma democracia sem partidos políticos. ${ }^{14}$ Nas eleições de outubro de 2006, as primeiras a exigirem que partidos alcançassem um mínimo de $5 \%$ dos votos válidos para deputado federal, como condição para manter o status pleno de partido, houve $46 \%$ de rotatividade na Câmara dos Deputados. Não obstante, os mesmos quatro partidos que dominaram a política brasileira desde a década de 1990 continuaram a dominar, demonstrando pouco da incerteza ou volatilidade eleitoral que era considerada um indicador do sentimento antipartidarista. O PSOL, um novo partido dissidente do PT em 2003, era o mais provável a receber os votos de protesto ou "outsiders", mas não alcançou o patamar de 5\%.

O auge da crise partidária na política brasileira recente ocorreu claramente em agosto de 2005. Isso foi particularmente evidente para o PT, que

${ }^{14}$ www.consulta.com.mx/interiores/14_entorno_int/ ei_latinbarometro05.html alcançara a presidência e níveis extraordinários de apoio partidário, e virou o segundo componente se esvair rapidamente. Mas a extensão da crise partidária era limitada em comparação com a da Argentina poucos anos antes. Cerca de 10.000 pessoas protestaram pelo impeachment de Lula em agosto; entretanto, não apenas deixaram de alcançar os milhões que haviam ajudado a derrubar o Presidente Collor em 1992 (Weyland, 1993), mas também enfrentaram igual número de contra-protestantes em apoio a Lula (Estado de São Paulo 17 e 20 ago. 2005). Esse momento agudo da crise foi formado pela lógica partidária corrente: os apoiadores históricos de Lula nas OSCs, decepcionados, não se mobilizaram a seu desfavor em parte porque isso implicaria aliarem-se ao PSDB contra o PT (Barbosa, 2006). Além disso, as pessoas que se mobilizaram para exigir o impeachment de Lula foram organizadas pelos dissidentes do PSOL e seus apoiadores partidários. Assim, mesmo no auge da crise, as OSCs brasileiras não tentaram organizar questionamentos diretos ao controle dos partidos sobre as funções governamentais, com exceção da escolha de alguns por migrar de partido.

\section{Formas emergentes de representação: recu- perar autonomia, fazer propostas}

Os vínculos históricos do PT com muitas das OSCs mais visíveis e ativas do Brasil significava que sua crise as atingia mais do que uma crise em outro partido as atingiria (Flynn, 2005). OSCs ajudaram a formar o PT como um instrumento de questionamento, primeiramente do governo militar e depois da desigualdade socioeconômica (Keck, 1992). Em níveis subnacionais, forneceu-lhes oportunidades singulares de participação política (Baiocchi, 2003; Nylen, 2000). As OSCs e o PT se uniram em diversas campanhas, desde as diretas já, na década de 1980, aos esforços de antiprivatização na década de 1990. As OSCs trabalharam de bom grado pela eleição de Lula em 2002 (Hochstetler, 2006b). Quatro anos depois, a Coordenação de Movimentos Sociais, um agrupa- 
mento de OSCs que estivera historicamente próximo do PT, propositadamente deixou de dar apoio direto no primeiro turno da campanha de reeleição de Lula, mas foi às ruas contra o retorno ao poder da coalizão PSDB-PFL. Em uma manha de discursos, organizações como a Central Única dos Trabalhadores (CUT), o Movimento dos Trabalhadores Sem Terra (MST) e a Marcha Mundial das Mulheres insistiam que somente a sua mobilização poderia mudar a política econômica, qualquer que fosse o resultado eleitoral..$^{15}$

Esse argumento, de que as OSCs isoladamente poderiam e de fato articulariam um modelo alternativo de desenvolvimento já estava em elaboração há algum tempo. Antes de o PT alcançar a presidência, era o maior agregador de tais afirmações, com vínculos próximos às OSCs (Nylen, 2003; Cabral, 2005). À medida que a campanha de 2002 de Lula progredia com diversos apaziguamentos de que ele continuaria as políticas econômicas neoliberais de FHC, um grande grupo de OSCs formou o Fórum Brasileiro do Orçamento em agosto (antes das eleições em outubro), para dar voz a um clamor por aumento nos gastos sociais. Também salientaram a necessidade de - e forneceram - maior debate público a respeito de questões orçamentárias, distribuindo 30.000 cópias de um livreto que descrevia conceitos, como o de superávit primário, em linguagem acessível (Fórum Brasileiro do Orçamento, 2004). Diversas ONGs, às vezes com trabalhos coincidentes, prepararam propostas econômicas alternativas: o Grito dos Excluídos, a Coordenação dos Movimentos Sociais, o Fórum Brasileiro do Orçamento, a Assembléia Popular, entre outros. No início do governo Lula, debatiam essas propostas em fóruns organizados pelo governo, como o Conselho de Desenvolvimento Econômico e Social e as consultas formais do governo acerca de seu Plano Plurianual 2004/ 2007: Um Brasil para Todos. Ao longo dos diferentes estágios, retiraram-se destas arenas para se concentrarem em iniciativas extra-governamentais,

${ }^{15}$ Observação de marchas de protesto em 28 de junho de 2006, em São Paulo, e entrevistas com organizadores (Barbosa, 2006; Marcelino; Coelho, 2006). afirmando que seus esforços estavam sendo desperdiçados internamente (Hochstetler, 2006b; Projeto Mapas, 2005, p.21).

O problema, do ponto de vista das OSCs, não era que não tinham um público. $\mathrm{O}$ governo Lula ansiava por ouvi-los e aplaudia seus esforços. O próprio Lula se encontrou regularmente com OSCs ao longo de suas gestões e enfatizou sua importância como vozes de valores e interesses sociais (Informes Abong n.246, 2004). O problema é que a articulação e a agregação de interesses das OSCs não produziam impacto nas escolhas de governo. Dezenas de milhares de organizações, em 33 redes que compõem a Inter-Redes, uma rede de redes, chegaram a essa conclusão quando formalmente renunciaram ao Plano Plurianual em que haviam trabalhado (Inter-Redes, 2004). Esse resultado demonstra a importância da persistente dominância dos partidos políticos sobre o espaço de governo.

Durante esse período, as OSCs reiteradamente tentaram mobilizar para a ação seu outro público, o público de massa, na esperança de utilizar amplas demandas públicas para forçar sua visão econômica. Um lugar para medir seu sucesso em alcançar esse público é no Grito dos Excluídos, uma marcha realizada anualmente em 7 de setembro, dia da Independência. Organizações próximas à Igreja Católica iniciaram o primeiro Grito em 1995, e ele se espalhou pelas Américas em 2000. Um ponto alto para essas mobilizações foi em 2002, quanto os organizações contaram 214.000 marchadores e mais de 10 milhões de participantes em um plebiscito sobre o Acordo de Livre Comércio das Américas. Mais de 98\% dos eleitores rejeitaram o tratado. ${ }^{16} \mathrm{Em} 2006$, os organizadores esperavam uma mobilização massiva de um milhão ou mais, para chamar a atenção para suas demandas de transformação econômica e política, e definiram regras rígidas proibindo os políticos de falaram - o que também era proibido pela lei eleitoral (Folha de São Paulo, 7 set., 2006). As es-

\footnotetext{
${ }^{16}$ www.gritodosexcluidos.com.br/gritoAmericas/grAm01.
Acesso em: 30 set. 2006 .
} 
timativas dos participantes, de fato, variavam entre a contagem inicial e otimista dos organizadores, em $300.000,{ }^{17}$ e a do Estado de São Paulo (7 set., 2006), que não chegava a 10.000. Os organizadores também superestimaram sua capacidade de atrair apoio popular na mobilização eleitoral acima referida - somente algumas centenas apareceram, ao invés dos cerca de 30.000 esperados. Os pobres brasileiros, um grande público em nome do qual essas organizações afirmam falar, são o maior bloco eleitoral de Lula nas pesquisas pré-eleitorais (DataFolha, 2006), em vez de "votarem com os pés" e inflarem tais protestos.

As OSCs brasileiras têm lutado para mobilizar seus públicos a respeito de questões econômicas desde muito antes da recente crise partidária. A principal mudança de pauta em virtude da crise é a renovação de uma iniciativa significativa de reforma política. Com muitas organizações e biografias pessoais de ativismo tendo origem na luta pela democracia, há um antigo interesse em instituições políticas e reforma política. Na década de 1990, boa parte dessa pauta era focada em esforços para obter e consolidar a representação popular e de OSCs nos processos decisórios do governo, como os ubíquos conselhos ou os processos de orçamento participativo (Baiocchi, 2003; Friedman; Hochstetler, 2002). Esses esforços freqüentemente contavam com o PT como colaborador ou mesmo proponente. A experiência das OSCs com o PT no poder, especialmente após a crise de corrupção, levou-as a repensar esse foco. Nos primeiros três anos de Lula no poder, quase 2 milhões de pessoas participaram nas conferências nacionais de sua gestão a respeito de diferentes questões (Reforma Política, 2006, Apêndice 3), mas, como notado acima, as OSCs quase sempre ficavam desapontadas com os resultados substantivos.

Em 2004, bem antes da crise de corrupção, a Ordem dos Advogados do Brasil (OAB) e a Congregação Nacional dos Bispos do Brasil (CNBB) propuseram uma lei que regulamentava o disposi-

${ }^{17}$ www.gritodosexcluidos.com.br/gritoBrasil/grBr30/. Acesso em: 30 set. 2006. tivo constitucional de iniciativas populares (art.14), enfatizando que a Constituição de 1988 insistia nas origens populares do poder, a ser exercido tanto direta quanto indiretamente. Quando veio a crise, a lei ainda estava percorrendo calmamente as Comissões do Congresso. Um grupo maior de OSCs passou então a ecoar por ela. Em junho de 2005, centenas delas assinaram uma Carta ao Povo Brasileiro, em que criticam fortemente a democracia representativa e clamavam por mecanismos políticos diretos. ${ }^{18}$ Diversos encontros de organizações ecoaram esses aspectos nos meses seguintes, ainda que em termos relativamente vagos (Hochstetler, 2006b).

Afora essa insatisfação generalizada, um grupo de OSCs tomou a iniciativa de trabalhar em propostas mais específicas. De agosto a novembro de 2005, 60 participantes que representavam 21 estados discutiram estratégias para lidar com a crise política. Como eles mesmos apontam, suas propostas iniciais de reforma política eram substancialmente mais amplas do que o processo paralelo de reforma dos partidos, que focava apenas a reforma eleitoral e partidária (Reforma Política, 2006, p.25). As OSCs propuseram diversas reformas que mudariam o funcionamento da democracia representativa - desde limites de mandato ao fim dos votos secretos - mas traziam propostas adicionais para a democracia direta, medidas participativas, democratização da informação e da comunicação e transparência judiciária. Incorporaram a proposta da OAB e do CNBB como parte de seu projeto maior. Ao longo do ano seguinte, diversos participantes se reuniram para discutir e refinar as propostas, graças a intensivas consultas e discussões no fórum social brasileiro e diversos fóruns de base geográfica. Ignoraram o calendário eleitoral nessas discussões, preferindo ter seu último encontro no final de novembro de 2006, quando já teriam se encerrado as eleições. As OSCs apresentaram suas propostas ao recém-eleito Congresso em março de 2007, recebendo considerável apoio parlamentar. Isso marcou seu retorno ao segundo mandato de

\footnotetext{
${ }^{8}$ www.lainsignia.org/2005/junio/ibe_087.htm. Acesso em: 23 jun. 2005.
} 
Lula como tendente a uma estratégia mais clássica de lobby, uma que reconhece o papel central das tomadas de decisão partidária. Em julho de 2007, a maior parte dos representantes do PT votou em sua primeira proposta, sobre uma reforma do sistema eleitoral de lista aberta. A reforma foi rejeitada pelo Congresso, juntamente com muitos membros de partidos da coalizão de governo de Lula (Vigna, 2007).

Como sugerem essas propostas de reforma, as OSCs brasileiras não têm a intenção de substituir instituições democráticas representativas, como os partidos políticos e o poder legislativo. Elas querem que tais instituições funcionem melhor e têm diversas idéias a respeito de como melhorar seu funcionamento. Ao mesmo tempo, as OSCs insistem que partidos políticos não podem monopolizar o exercício da soberania popular. Querem consideravelmente mais participação direta para cidadãos brasileiros individuais. Também prevêem uma necessidade contínua de pressão da sociedade civil organizada, independentemente do partido que vencer as eleições.

\section{CONCLUSÕES}

Os partidos políticos podem deixar muitas lacunas de representação. No Brasil e na Argentina, tais lacunas estão sempre presentes, mas as recentes crises partidárias acentuaram a sensação dos cidadãos de que seus partidos políticos não as preenchem adequadamente. Em ambos os países, as OSCs se prontificaram a preencher algumas das lacunas, ainda que o tenham feito de formas diferentes. Na Argentina, cidadãos formaram novas OSCs para contornar a representação partidária, rejeitando a classe política em favor de se representarem diretamente. OSCs novas e já existentes detinham uma posição especial como atores éticos, de princípios. Ao longo do tempo, porém, os partidos se reorganizaram e até conseguiram cooptar algumas das novas OSCs. Outras continuam, agora trabalhando em paralelo aos representantes partidários. No Brasil, as OSCs nunca se apresentaram como alternativas organizacionais aos partidos, mas lutaram para representar valores e idéias que não estavam sendo representados. Esses incluíam tanto propostas econômicas substantivas e propostas para melhorar o processo político, inclusive o processo de representação partidária.

Essas experiências corroboram nosso argumento teórico mais amplo, de que as OSCs podem operar como mecanismos de representação, ainda que não da mesma forma que partidos. Tanto cidadãos quanto governos têm reconhecido que as OSCs dão voz a importantes idéias e têm respondido às suas propostas. OSCs deram voz aos cidadãos no sistema político. No final das contas, as funções representativas das OSCs não substituíram a representação partidária de maneira perene. Em vez disso, sua representação parece complementar a dos partidos, com cidadãos utilizando ambos os mecanismos para influenciar os resultados políticos.

(Recebido para publicação em janeiro de 2008) (Aceito em março de 2008)

\section{REFERÊNCIAS}

ALVAREZ, Sonia E. Engendering democracy in Brazil: women's movements in transition politics. Princeton: Princeton University Press, 1990.

AMES, Barry. The deadlock of democracy in Brazil. Ann Arbor: University of Michigan Press, 2001.

AMORIM NETO, Octavio. Critical debates: The puzzle of party discipline in Brazil. Latin American Politics and Society, v.44, n.1, p.127-144, 2002.

ANTOKOLETZ, María Adela. Communications director, mothers of the Plaza de Mayo - founding line. Interview, Buenos Aires, july 3, 2006.

ASOCIACION POR LOS DERECHOS CIVILES. La corte y los derechos. Buenos Aires: Siglo Veintiuno Editores, 2005.

AUYERO, Javier. Protest in contemporary Argentina. A contentious repertoire in the making. In:

FERNANDEZ-KELLY, P; SHEFNER, J. (Ed.) Out of the shadows: political action and the informal economy in Latin America. [S.l.]; University park Penn State Press, 2005.

Poor people's politics. Durham and London: Duke University Press, 2001.

AVRITZER, Leonardo. Democracy and the public space in Latin America. Princeton: Princeton University Press, 2002.

BAIOCCHI, Gianpaolo. (Ed.) Radicals in power: the worker's party and experiments in urban democracy in Brazil. New York: Palgrave, 2003b. 
BARBOSA, Benedito (Coord.) Central of Popular Movements and National Movement for Urban Reform. Interview, São Paulo, june 29, 2006.

BARTOLINI, Stefano, and Peter Mair. Challenges to contemporary political parties. In: DIAMOND L. GUNTHER, R. (Ed.) Political parties and democracy. Baltimore: Johns Hopkins University Press, 2001.

BERGEL, Pablo. Nuevas Formas Asociativas: asambleas vecinales y Movimientos de Trabajadores Desocupados (MTD). In: GONZÁLEZ BOMBAL, I. (Ed.). Nuevo Movimientos Sociales e ONGs en la Argentina de la crisis. Buenos Aires: CEDES, 2003.

BIELSA, Rafael A. et al. Que son las asambleas populares. Buenos Aires: Ediciones Continente, 2002.

BLUMENFELD, José. Member, active memory. Interview, Buenos Aires, july 4, 2006.

BONNER, Michelle D. Defining rights in democratization: the argentine government and human rights organizations. Latin American Politics and Society, [S.l.], v.47, n.4, p.55-76, 2005

BORLAND, Elizabeth. Mature Resistance: The Madres de Plaza de Mayo in Argentina. Latin American Studies Association Meeting, San Juan, Puerto Rico, 2006.

CABRAL, Gilda. Technical advisor, CFEMEA; executive secretary, Brazilian Budget Forum (FBO). Interview, Brasília aug. 9, 2005.

CALVO, Ernesto; ESCOLAR, Marcelo La nueva política de partidos en la Argentina: crisis política, realineamentos partidarios y reforma electoral. Buenos Aires: Prometeo Libros, 2005

CAMARERO, Hernàn; POZZI, Pablo; SCHNEIDER, Alejandro. Unrest and repression in Argentina. New Politics, Usuhuaia, Argentina, v.7, n.1, 1998. Disponível em: www.wpunj.edu/newpol/issue25/camare25.htm

CAREY, John.. Discipline, accountability, and legislative voting in Latin America. Comparative Politics, [S.l.], v.35, n.2, p.191-211, 2003.

CHALMERS, Douglas A. et al (Ed.) The new politics of inequality in Latin America: rethinking participation and representation. Oxford: Oxford University Press, 1997.

CHANDOKE, Neera. Revisiting the crisis of representation thesis: the Indian context. Democratization v.12, n.3 .308-330, 2005

Centro de Implementación de Políticas Públicas para la Equidad y el Crecimiento. Directorio de ONGS vinculadas con políticas públicas, 2006. Disponível em: www.directoriodeongs.org/

COELHO, Sonia. Sempreviva Feminist Organization (SOF) and World March of Women. Interview, São Paulo, june 29, 2006.

CRISP, Brian F. et al. Vote-seeking incentives and legislative representation in six presidentialdemocracies. Journal of Politics, [S.l.], v.66, n.3, p.823-846. 2004.

DALTON, Russell J.; WATTENBERG, Martin P. Unthinkable Democracy: Political Change in Advanced Industrial Democracies. In: ; (Ed.) Parties without partisans: political change in advanced industrial societies. Oxford: Oxford University Press, 2000.

; SCARROW, Susan E.; CAIN, Bruce E. Advanced democracies and the new politics. Journal of Democracy, Washington, v.15, n.1, p. 124-138, 2004.

DE PIERO, Sergio. Organizaciones de la sociedad civil: tensiones de una agenda en construcción. Buenos Aires: Paidós, 2005.

DELAMATA, Gabriela. The Organizations of unemployed workers in greater Buenos Aires. In: CLAS working papers. Berkeley, California: Center for Latin American Studies, 2004.

DI MARCO, Graciela. Igualdad de género y movimientos sociales en Argentina. Paper Read at Latin American Studies Association Meeting, San Juan, Puerto Rico, 2006. FIGUEIREDO, Argelina C.; LIMONGI, Fernando. Presidential power, legislative organization, and party behavior in Brazil. Comparative Politics, Boston, v.32, n.2, p.151-170, 2000

FÓRUM Brasileiro do Orçamento. Superávit primário. Cadernos para Discussão. Brasilía, 2004.

FOWERAKER, Joe; KRZNARIC, Roman. The uneven performance of third wave democracies: electoral politics and the imperfect rule of law in Latin America. Latin American Politics and Society, Coral Gables, University of Miami, v. 44, n.3, p.29-59, 2002.

FRIEDMAN, Elisabeth Jay; HOCHSTETLER, Kathryn. Assessing the third transition in Latin American Democratization: civil society in Brazil and Argentina. Comparative Politics, New York, v.35, n.1, p.21-42, 2002.

FUCHS, Dieter; KLINGEMANN, Hans-Dieter. Citizens and the state: a relationship Transformed. In (Ed.) Citizens and the state. Oxford, UK: Oxford Un' $\overline{\text { niversity }}$ Press, 1995

GAUDIN, Andres. The kirchner factor. NACLA, [S.l.], v.38, n.4, p.16-19, 2005

GOLDSTONE, Jack A.; THOMAS, Cliva S. More social movements or fewer? Beyond political opportunity structure to relational fields. Theory and Societ, Norwell, n.33, p.333-365, 2004.

GONZALES BOMBAL, Inés (Ed.). Nuevos movimientos sociales y ONGs en la Argentina de la crisis. Buenos Aires: CEDES, 2003.

GURZA LAVALlE, Adrián; HOUTZAGER, Peter P. CASTELLO, Graziela. Representação política e organizacões civis: novas instâncias de mediacão e os desafios d legitimidade. Revista Brasileira de Ciências Sociais, São Paulo, v.21, n.60, 2006.

HELLMAN, Judith Adler. The study of new social movements in Latin America and the question of autonomy. In: ESCOBAR, A.; ALVAREZ, S. E. (Ed.) The making of social movements in Latin America: identity, strategy, and democracy. Boulder: Westview Press, 1992.

HOCHSTETLER, Kathryn. Rethinking presidentialism: challenges and presidential falls in South America. Comparative Politics, New York, v.38, n.4, p.401-418, 2006a.

Organized civil society in Lula's Brazil. PAPER PREPARED FOR PRESENTATION AT THE LATIN AMERICAN STUDIES ASSOCIATION CONFERENCE, [S.l.], 2006b.

IÑIGO CARRERA, Nicolás; COTARELO, María Celia. La insurrección espontánea, Argentina Diciembre 2001. Descripción, periodización, conceptualización. PIMSA, Documento de Tranbajo, n.43, 2003.

INTER-REDES. 2005. Comunicado Inter-redes e ABONG 2004. Disponível em: www.forumfbo.org.br/publique/cgi/ cgilua.exe/sys/start.htm?infoid $=35 \&$ sid $=10$

JEIFETZ, Néstor R. President, Movement of Residents and Tenants (MOI). Interview, Buenos Aires, july 9, 2006.

KECK, Margaret. The worker's party and democratization in Brazil. New Haven: Yale University Press, 1992.

KITSCHELT, Herbert. Landscapes of political interest intermediation: social movements, interest groups, and parties in the early twenty-first century. In: IBARRA, P (Ed.) Social movements and demcracy. New York; 
Basingstoke: Palgrave Macmillan, 2003.

Linkages between citizens and politicians in democratic politics. Comparative Political Studies, [S.l.], Sage, v.33, n.6/7, p.845-879, 2000.

KOROL, Claudia (Ed.). Obreros sin patron: sistematizacion de la experiencia de los obreros y obreras de Zanon. Buenos Aires: Ediciones Madres de Plaza de Mayo, 2004.

KURTZ, Marcus. The dilemmas of democracy in the open economy: lessons from Latin America. World Politics, Baltimore, v.56, n.1, p.262-302, 2004.

LAVACA. Sin patron: fabricas y empresas recuperadas por sus trabajadores. Una historia, una guia. Buenos Aires: Lavaca Editora, 2004

LAWSON, Kay; POGUNTKE,Thomas (Ed.). How political parties respond: interest aggregation revisited. London; New York: Routledge, 2004.

; MERKL, Peter H. (Ed.) When parties fail: emerging alternative organizations. Princeton: Princeton University Press, 1988.

LESCANO, Escano, Cristina. El ceibo neighborhood work Interview, Buenos Aires, july 6, 2006.

LEVITSKY, Steven. Organization and labor-based party adaptation: the transformation of Argentine peronism in comparative perspective. World Politics, Baltimore, v.54, n.1, p.27-56, 2001a.

Inside the black box: recent studies of Latin American party organizations. Studies in Comparative International Development [S.1.], v.36, n.2, p.92-110, 2001b.

LEVITSKY, Steven. An “organized disorganisation”: informal organisation and the persistence of local party structures in Argentine peronism. Journal of Latin American Studies, [S.l.], v.33, n.1, p.29-65, 2001c.

LOZANO, Claudio et al. Protestas sociales en la Argentina contemporanea: principales caracteristicas. abril/junio, 2004. Buenos Aires: CTA Instituto de Estudios y Formacion, 2004

LUCERO, José Antonio. High anxiety in the Andes: crisis and contention in Ecuador. Journal of Democracy, Washington, n.12, apr., p.59-73, 2001.

MANIN, Bernard. Principles of representative government. Cambridge, UK: Cambridge University Press, 1997.

MAINWARING, Scott. The surprising resilience of elected governments. Journal of Democracy, Washington, v.10, n.3, p.101-114, 1999a.

Rethinking party systems in the third wave of democratization: the case of Brazil. Stanford: Stanford University Press, 1999b.

The crisis of representation in the Andes. Journal of Democracy, Washington, v.17, n.3, p.13-27, 2006.

; SCULLY, Timothy R. (Ed.). Building democratic institutions: party systems in Latin America. Stanford, CA: Stanford University Press, 1995.

MARECLINO, Maria Fernanda. Sempreviva Feminist Organization (SOF) and World March of Women. Interview, São Paulo, june 29, 2006.

MARTIN VEZZULLA, Juan. Legal Advisor, Environment and Natural Resources Foundation (FARN). Interview, Buenos Aires, july 12, 2006

MCGUIRE, James W. Political parties and democracy in Argentina. In: MAINWARING, Scott; SCULLY, T. R. (Ed.) Building democratic institutions: party systems in Latin America. Stanford, CA: Stanford University Press, 1995.
MUSTAPIC, Ana Maria. Inestabilidad sin colapso. La renuncias de los presidentes: Argentina en el año 2001. Desarrollo Económico, Buenos Aires, v.45, n.178, p.263279, 2005.

NORDEN, Deborah L. Democracy beyond elections? The shifting nature of representation in Argentina. PAPER PREPARED FOR PRESENTATION AT THE LATIN AMERICAN STUDIES ASSOCIATION CONFERENCE. [S.l.], 2006.

NYLEN, William R. The making of al loyal opposition: The workers' party (PT) and the consolidation of democracy in Brazil. In: KINGSTONE, P. R.; POWER, T. J. (Ed.) Democratic Brazil: actors, institutions, and processes. Pittsburgh: University of Pittsburgh Press, 2000.

O’DONNEL, Guillermo. Horizontal accountability in new democracies. Journal of Democracy, Washington, v.9, n.3, p.112-126, 1998.

OJEDA, Fernando. El ceibo neighborhood work. Interview, Buenos Aires, july 6, 2006.

PANEBIANCO, Angelo. Political parties: organization and power. Cambridge: Cambridge University Press, 1988.

PANIZZA, Fransisco. Unarmed utopia revisited: the resurgence of left-of-centre politics in Latin America. Political Studies, [S.l.], v.53, n.4, p.716-734, 2005

PEARCE, Jenny. Debate: collective action or public participation? Complementary or contradictory democratisation strategies in Latin America? Bulletin of Latin American Research, [S.1.], v.23, n.4, p.483-504, 2004.

PERUZZOTTI, Enrique. Civil society, Representation and accountability: restating current debates on the representativeness and accountability of civic associations. forthcoming. In: VAN TUIIL, P.; JORDAN L. (Ed.) The politics of NGO accountability. London: Earthscan, 2006.

Towards a new politics: citizenship and rights in contemporary Argentina. Citizenship Studies, [S.1.], v.6, n.1, p.77-93, 2002

PITKIN, Hanna Fenichel. The concept of representation. Berkeley: University of California Press, 1967.

POGUNTKE, Thomas. European Journal of Political Research, [S.1.], v.29, n.3, p.319-344. 1996.

POWELL, G. Bingham. Political representation in comparative politics. Annual Review of Political Science, Paolo Alto, n.7, p.273-96, 2004.

PRZEWORSKI, Adam; STOKES, Susan C.; MANIN, Bernard (Ed.) Democracy, accountability, and representation. Cambridge, UK: Cambridge University Press, 1999.

RACHID, Maria. President, Argentine federation of lesbians, gays, bisexuals and trans. Interview, Buenos Aires, aug., 6, 2007

REFORMA política: construindo a plataforma dos movimentos sociais para a reforma do sistema político no Brasil - reflexões para o debate. 2006. Disponível em: www.abong.org

REHFELD, Andrew. Towards a general theory of political representation. Journal of Politics [S.1.], v.68, n.1, p.1-21, 2006.

ROBERTS, Kenneth M. Party-society linkages and the transformation of political representation in Latin America. Canadian Journal of Latin American and Caribbean Studies, [V.1.], v.27, n.53, p.9-34, 2002.

RODRIGUEZ, María Carla. Co-founder, Movement of Residents and Tenants (MOI); Researcher, Gino Germani Institute, University of Buenos Aires. Interview, Buenos Aires, july 9, 2006 
SABA, Roberto. Executive Director, Association of Civil Rights (ADC). Interview, Buenos Aires, july 12, 2006.

SAMUELS, David. Sources of mass partisanship in Brazil. Latin American Politics and Society, Coral Gables, University Miami, v.48, n.2, p.1-27, 2006.

SANCHEZ, Omar. Argentina's landmark 2003, presidential election: renewal and continuity. Bulletin of Latin American Research, [S.l.], v.24, n.4, p. 454-475, 2005.

SANCHÍS, Norma. Regional Coordinator, International Network of Gender and Commerce. Interview, Buenos Aires, july 12, 2006.

SARDÁ, Alejandra. Resisting kirchner's Recipe (sometimes): 'LGBTTTI' Organizing in Argentina. NACLA Report on the Americas, [S.1.], v.40, n.2, p.30-32, 42, 2007.

SAWARD, Michael, ed. Democratic innovation deliberation, representation and association. New York: Routledge, 2001.

SCHVARTZMAN, Elsa. Member, Forum for Reproductive Rights and National Campaign for for the Right to Legal, Safe, and Free Abortion. Interview, Buenos Aires, aug., 6, 2007.

SECCHI, Pablo. Co-coordinator, Political Action Area Citizen Power. Interview, Buenos Aires, july 3, 2006.

SITRIN, Marina [Ed.]. Horizontalidad: voces de poder popular. Buenos Aires: Cooperativa Chilavert Artes Graficas, 2005.

SMULOVITZ, Catalina; PERUZZOTTI, Enrique. Societa accountability in Latin America. Journal of Democracy, Washington, p.147-158, 2000.

SUNDHEIM, Marcelo. Secretary, Homosexual Community of Argentina (CHA). Interview, Buenos Aires, july 5, 2006.

SVAMPA, Maristella. La sociedad excluyente: la Argentina bajo el signo del neoliberalismo. Buenos Aires: Taurus, 2005.

; PEREYRA, Sebastián. La experiencia piquetera: dimensiones y desafíos de las organizaciones de desocupados en Argentina. Medio Ambiente y Urbanización, Buenos Aires, v.61, n.1, p.97-112, 2005.

TAYLOR-ROBINSON, Michelle M. Old parties and new democracies: do they bring out the best in each other? Party Politics, [S.l.], v.7, n.5, p.581-604. 2001.

THOMASs, Clive S. Studying the political party-interest group relationship. In: . (Ed.). Political parties and interest groups. Boulder: Lynne Rienner. 2001.

TORRE, Juan Carlos. Los heurfanos de la política de partidos. sobre los alcances y la naturaleza de la crisis de representación partidaria. Desarrollo Económico, Buenos Aires, v.42, n.168, p.647-665, 2003.

TURNER, Frederick; CARBALLO, Marita. Argentina: economic disaster and the rejection of the political class. Comparative Sociology, [S.1.], v.4, n.1/2, p.175-206, 2005.

VALENTE, Marcela. Argentina: human rights trials trigger wave of threats. Inter Press Service New Agency, [S.1.], 10/ $4 / 2006$.

VAN COTT, Donna Lee. From movements to parties in Latin America: the evolution of ethnic politics. Cambridge, UK: Cambridge University Press, 2005.

VERDÚ, Maria del Carmen. Spokesperson and lawyer. Coordinator Against Police and Institution Repression (CORREPI). Interview, Buenos Aires, july 10, 2006.

VIGNA, Edélcio. O futuro da reforma política. Disponível em: www.ciranda.net/ spip/article1422.html. Acesso em: 20 sept., 2007.

WALGER, Sylvina, PERUZZOTTI, Enrique. El govierno actua sin el debido control. La Nacion, [S.l.], 09/9/2006.

WEBB, Paul. Political parties and democracy: the ambiguous crisis. Democratization, [S.l.], v.12, n.5, p.633650, 2005.

WEYLAND, Kurt. The rise and fall of President Collor and its impact on Brazilian democracy. Journal of Interamerican Studies and World Affairs, [S.1.], n.35, p.137, 1993.

ZIBECHI, Raúl. Subterranean echoes: resistance and politics "Desde el Sótano." Socialism and Democracy [S.l.], v.19, n.3, p.13-39, 2005. 
REPRESENTAÇÃO, PARTIDOS E SOCIEDADE CIVIL NA ARGENTINA E BRASIL

Kathryn Hoschstetler, Elisabeth Jay Friedman

Este artigo questiona se as organizacões da sociedade civil (OSCs) podem e society paper questions if the civil cumprem o papel de exercer uma função OSCs) can and do accomplish their role de representação em tempos de crise dos of exercising a representative function partidos políticos. Para tanto, ele exami- in times of crisis of the political parties. na práticas recentes de representação no In order to do so, it examines recent Brasil e na Argentina, dois países onde practices of representation in Brazil and os partidos políticos têm experimentado in Argentina, two countries where crises agudas depois de décadas de avali- political parties have gone through acute ações ambíguas a respeito de seus siste- crises after decades of ambiguous mas partidários. Em tais momentos, evaluations regarding their partidary qualquer substituição de partidos por systems. In such moments, any OSCs deveria ser facilmente identificável. substitution of parties for OSCs should Inicialmente, examinam-se as funções e be easily identifiable. Initially, the o potencial de representação das OSCs, functions and the representative usando o modelo de partido político como potential of OSCs are examined, using referência. Em seguida, argumenta-se a the political party model as reference. partir de surveys já publicados e pesquisa Then, it is shown from already published de campo inédita, numa comparação surveys and unpublished field research focada em quão bem os partidos e OSCs in a comparison focused in how well têm desempenhado suas funções públi- the parties and OSCs have been carrying cas e organizacionais no Brasil e na Ar- out their public and organizationa gentina. A conclusão é a de que as OSCs functions in Brazil and in Argentina. não substituem os partidos como meca- The conclusion is that OSCs do not nismos de representação de interesses e substitute parties as mechanisms of valores dos cidadãos - e nem ao menos representation of citizens' values and tentam fazer isso, exceto por um breve interests - and do not even try to do período, no auge da crise na Argentina. that, except for a brief period, in the Em ambos os países, porém, as OSCs peak of the crisis in Argentina. In both melhoram a qualidade de representação countries, however, OSCs improve the dos cidadãos. quality of the citizens' representation.

PALAVRAS-CHAVE: representação, sociedade KEYwordS: representation, civil society, civil, Brasil, Argentina, partidos políticos. Brazil, Argentina, political parties.
REPRÉSENTATION, PARTISET SOCIÉTÉ CIVILE, EN ARGENTINE ET AU BRÉSIL

\section{Kathryn Hoschstetler,}

Elisabeth Jay Friedman

La question abordée dans cet article est de savoir si les organisations de la société civile (OSCs) peuvent et exercent effectivement une fonction de représentation en temps de crise des partis politiques. Dans ce but, on analyse les pratiques récentes de représentation au Brésil et en Argentine, deux pays où les partis politiques ont souffert de crises aiguës après des décennies d'évaluation ambiguë de leurs systèmes de partis. Au cours de ces crises, le remplacement d'un parti, quel qu'il soit, par ces OSCs devrait pouvoir être facilement identifié.Tout d'abord, ce sont les fonctions et le potentiel de représentation des OSCs qui sont analysés, en utilisant comme référence le modèle du parti politique. Ensuite, les arguments proviennent des surveys déjà publiés et d'une recherche inédite sur le terrain, en faisant une comparaison centrée sur le bon développement des fonctions publiques et organisationelles des partis et des OSCs, au Brésil et en Argentine. On en arrive à la conclusion que les OSCs ne remplacent pas les partis en tant que mécanismes de représentations des intérêts et des valeurs des citoyens - ni essaient de le faire, sauf au cours d'une périodes très brève, lorsque la crise a atteint son point culminant en Argentine. Les OSCs ont cependant amélioré la qualité de la représentation des citoyens, dans ces deux pays.

MoTS-CLÉs: représentation, société civile, Brésil, Argentine, partis politiques. 